\title{
Rectal Prolapse of the Child at the Center University Hospital of Brazzaville
}

\author{
Mieret Jean Claude ${ }^{*}$, Moyen Engoba ${ }^{2}$, Koumbourou Judicaël'2, Antsiemi Yves ${ }^{1}$, \\ Mboutol Mandavo Carine1, Yaokreh Jean Baptiste ${ }^{3}$, Moyen Georges ${ }^{2}$ \\ ${ }^{1}$ Department of Pediatric Surgery, Center University Hospital of Brazzaville, Brazzaville, Congo \\ ${ }^{2}$ Pediatric Intensive Care Unit, Center University Hospital of Brazzaville, Brazzaville, Congo \\ ${ }^{3}$ Department of Pediatric Surgery, Yopougon University Hospital, Abidjan, Côte d'Ivoire \\ Email: *jmieret@yahoo.fr
}

How to cite this paper: Claude, M.J., Engoba, M., Judicaël, K., Yves, A., Carine, M.M., Baptiste, Y.J. and Georges, M. (2017) Rectal Prolapse of the Child at the Center University Hospital of Brazzaville. Open Journal of Pediatrics, 7, 359-362. https://doi.org/10.4236/ojped.2017.74041

Received: October 8, 2017

Accepted: December 25, 2017

Published: December 28, 2017

Copyright (C) 2017 by authors and Scientific Research Publishing Inc. This work is licensed under the Creative Commons Attribution International License (CC BY 4.0)

http://creativecommons.org/licenses/by/4.0/

\begin{abstract}
Summary: The aim of this work was to determine the frequency of rectal prolapse and to describe the therapeutic aspects. Material and Methods: A descriptive study with a retrospective collection was carried out between January 2013 and May 2016 in 29 months in the pediatric surgery department at the Center University Hospital of Brazzaville. Children between the ages of 1 and 15 years of age, treated for rectal prolapse and whose records were exploitable were included. The variables studied were: age, gender, parental socio-economic status, consultation time, preference factors, pre-admission treatment, treatment initiated and progression. Results: In 29 months, 22 cases of rectal prolapse were collected, i.e. a hospital frequency of $0.96 \%$. The mean age was 4.5 years extremes ( 1 and 11 years). The average time of consultation was 5 days extremes (1 and 21 days). Diarrhea 5 cases (23\%), constipation diarrhea 3 cases (14\%), constipation 10 cases (45\%), bronchopneumopathy 4 cases (18\%). The treatment was surgical according to the Thiersch technique in all cases. The evolution was favorable. Conclusion: Rectal prolapse, a benign pathology, is relatively uncommon. Constipation remains the main factor favoring the need to take care of upstream. Treatment by the Thiersch method remains the first choice in children.
\end{abstract}

\section{Keywords}

Rectal Prolapse, Frequency, Children

\section{Introduction}

The rectal prolapse, protrusion of all layers of the rectum through the anus is a very disabling pathology. Its incidence varies between $0.25 \%$ and $0.45 \%$ [1]. Its 
diagnosis is easy, often made by the parents as a sort of red mucous membrane in ferrule during defecation. It's well codified treatment relies essentially on strapping, a simple, inexpensive, radical, fast and reliable method. The evolution is favorable.

The aim of this first work was to determine the frequency of the rectal prolapse in children and to describe the therapeutic aspects at the Center University Hospital of Brazzaville.

\section{Material and Methods}

We carried out a descriptive study with a retrospective collection between January 2013 and May 2016 in 29 months in the pediatric surgery department at the Center University Hospital of Brazzaville. Children aged 0 to 15 years treated for the rectal prolapse and whose records were exploitable were included. Records of children treated for prolapse intussusception were not included.

Our data sources were medical records and operational records. The variables analyzed were: frequency, age, gender, parental socio-economic status, time to consultation, preference factors, pre-consultation treatment, hospital treatment, and outcome.

Treatment consisted in all cases of dietary advice, administration of transit regulator followed by anal strapping. The method used to perform the strapping was that of Thiersch which is done in the operating room, under general anesthesia with a mask. With the patient in supine position, a number 2 absorbable yarn is passed under the skin around the anal margin and tightened on the anal canal calibrated by the finger to reduce the diameter of the anal orifice.

\section{Results}

During the study period, of 2276 children admitted to the service, 22 were admitted for the rectal prolapse, a frequency of $0.96 \%$. There were 9 boys and 13 girls (sex ratio: 0.69 ). The mean age was 4.5 years extreme ( 1 and 11 years). The distribution by age group is shown in Table 1. Parents had a low socioeconomic level in all cases. The average time of consultation was 5 days extremes ( 1 and 21 days). The reason for consultation was in all cases, an external, intermittent, permanent rectal mucosa (Figure 1). Diarrhea 5 cases (23\%), diarrhea alternating constipation 3 cases (14\%), constipation 10 cases (45\%), and chronic cough 4 cases $(18 \%)$. Prior to the consultation, children were treated with $n=12$ plants

Table 1. Patient distribution by age range.

\begin{tabular}{ccc}
\hline Age & N & Percentage (\%) \\
\hline Less 2 years & 2 & 9 \\
Between 2 - 5 years & 17 & 77 \\
Greater 5 years & 3 & 14 \\
Total & 22 & 100 \\
\end{tabular}




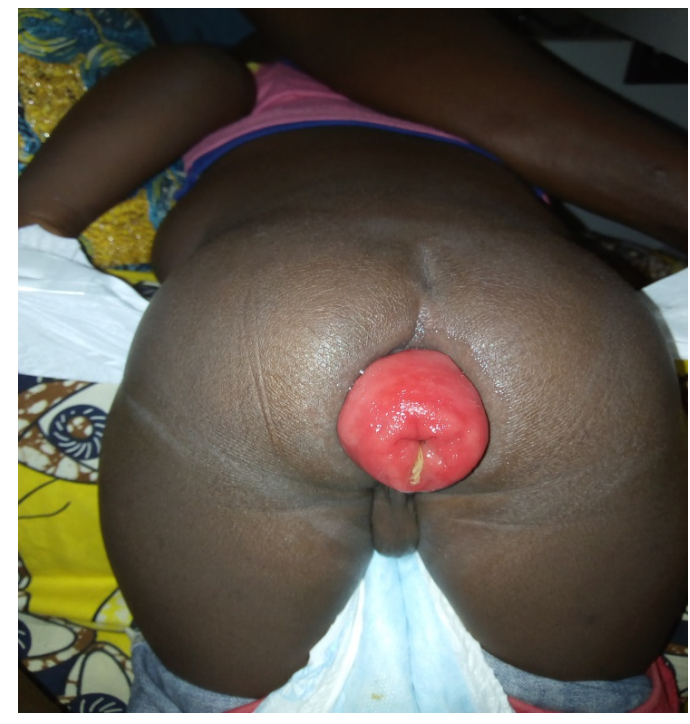

Figure 1. Rectal prolapsed.

(54.5\%), free laxatives obtained $\mathrm{n}=6(27.3 \%)$, and children received no treatment $\mathrm{n}=4(18.2 \%)$. We performed surgical treatment in all cases. Evolution was favorable in all cases, no recurrence was noted.

\section{Discussion}

The rectal prolapse is a relatively infrequent disease [1]. Its hospital frequency varies according to the series; it is 43 cases per year according to Ahmed [2], 5 cases per year according to Koivusalo et al. [3] and 11 cases per year in ours. The rectal prolapse is a benign condition that affects both boys and girls of all ages [2] [4]. The average age of occurrence noted in our study (4.5 years) is similar to that found in Togo et al. [5] in Mali (4.3 years).

The late consultation, known in Africa was found in our work. Population ignorance, poverty, socio-cultural factors and dysfunctional health structures would explain this delay. The rectal prolapse in children, especially infants and young children is favored by dietary and hygienic factors [6]. In our study, as in most literature series, constipation is the main factor [3] [4] [5] [7]. Chronic diarrhea, dysentery and malnutrition are factors associated with the development of the rectal prolapse in children, especially in developing countries [7]. However, the child's prolapse may be idiopathic [4] [8], as reported by Koivusal and Shah studies in $19 \%$ and $31 \%$ of cases [3] [7]. The occurrence of prolapse in the course of bronchopulmonary disorders in this series may be explained by intra-abdominal hyperpressure during coughing.

Therapeutically, $81.8 \%$ of the patients use self-medication because of low purchasing power, in the absence of a social protection system, all health expenditure (consultation, complementary examinations, pharmaceuticals) being to the parents.

Treatment of the rectal prolapse requires prior medical care obeying the hygiene-dietetic rules that must be explained to parents [6] [8]. For Togo et al. [5] in Mali, medical treatment was done in $90 \%$ of cases. On the other hand Dieth et 
al. [9] in Cote d'Ivoire, used sclerosing injections in $100 \%$. The techniques of rectopexy of Orr-Loygue or resection of the proliferated pudding [10] are excessive given the benignity of the affection. Lochart Murmmery's method was used in the study of Togo et al. [5]. The method of Aboulola et al. [11], which involves introducing a large rectal probe fitted into the suture for 8 days, through the reduced prolapse, is a source of numerous recurrences.

In our study, the therapeutic protocol consisted of dietary hygiene measures followed by intervention by the Thiersch technique. This technique (strapping) is fast and simple to achieve with a success rate of $100 \%$.

\section{Conclusion}

Rectal prolapse remains a benign pathology, uncommon in pediatric proctology practice. Children aged 2 to 5 years are the most affected and constipation remains the main factor favoring. The treatment of choice is the method of Thiersch, because it is easy to perform, non-aggressive, effective and uncomplicated.

\section{References}

[1] Celine, D.C., Nicolas, D. and Dieter, H. (2013) Rectal Prolapse: Update. Forum Medical Switzerland, 13, 1029-1032.

[2] Ahmed, E.L. (2003) Closed Rectosacropexy for Rectal Prolapse in Children. Surgery Today, 33, 642-644. https://doi.org/10.1007/s00595-003-2548-9

[3] Koivusalo, A., Pakarinen, M., Rintla, R. (2006) Laparoscopic Suture Rectopexy in the Treatment of Persisting Rectal Prolapse in Children. Surgical Endoscopy, 20, 960-963. https://doi.org/10.1007/s00464-005-0424-y

[4] Antao, B., Bradley, V., Roberts, J.P. and Shawis, R. (2005) Management of Rectal Prolapse in Children. The American Society of Colon and Rectal Surgeons. Diseases of the Colon \& Rectum, 48, 1620-1625. https://doi.org/10.1007/s10350-005-0074-0

[5] Togo, A., Coulibaly, Y., Keita, M., Diakité, I., Dembelle, B.T., Bogola, A. and Diallo, G. (2011) Rectal Prolapse of the Child at the CHU Gabriel Touré. Medecined' Afrique Noire, 58, 253-257.

[6] Rached, B., Achref, D., Zeined, M., Ghofrane, T., Lassaad, G., Nafaa, G. and Mohamed, T.K. (2016) Chronic Rectal Prolapse of the Young Adult: About a Case and Review of the Literature. Pan African Medical Journal, 2016, 1-5.

[7] Shah, A., Parikh, D., Jawaheer, G. and Gornall, P. (2005) Persistent Rectal Prolapse in Children: Sclerotherapy and Surgical Management. Pediatric Surgery International, 21, 270-273. https://doi.org/10.1007/s00383-005-1384-y

[8] Guys, J.M. and Helardot, P.G. (1996) The Pediatric Rectum Sauramps Medical. Pediatric Surgery Service in Saint-Vincent de Paris, Montpellier.

[9] Dieth, A.G., Da, S.-A., Ouattara, O.C., Aguehounde, C. and Roux, C. (1999) The Value of Scleranase in the Treatment of Rectal Prolapse in Children. Medicine of Black Africa, 46, 337-339.

[10] Frederic, M., Laurent, B., Rasa, Z., Laurent, B., Christophe, D. and Patrick, B. (2005) Long Term Result of Delorme's Procedure and Orr-Loygue Rectopexy to Treat Complete Rectal Prolapse. Colon and Rectum, 48, 1785-1790. https://doi.org/10.1007/s10350-005-0088-7

[11] Aboulola, M., Boukheloua, B. and Izem, K. (1978) A Simple Original Method of Treating Irreducible Rectal Prolapse in Children. Annale Algerienne of Surgery, XII, 167-171. 